\title{
Composite copper/stainless steel coated powders
}

\author{
Mariana Matos, José M. Castanho*, Maria T. Vieira \\ ICEMS-Materials and Surface Engineering Group, Mechanical Engineering Department, Polo II, \\ University of Coimbra, Coimbra, Portugal
}

\section{A R T I C L E I N F O}

\section{Article history:}

Received 30 August 2007

Received in revised form 23 July 2008

Accepted 2 August 2008

Available online $\mathrm{xxx}$

\section{Keywords:}

Metals

Thin films

Vapour deposition

Powder metallurgy

$\mathrm{X}$-ray diffraction

\begin{abstract}
A B S T R A C T
The present research work concerns the development of new composites based on austenitic stainless steel (SS) or copper $(\mathrm{Cu})$ microsized powders coated with thin nanostructured layers of copper or stainless steels, respectively. A home-manufactured magnetron sputtering system equipped with a powder vibration device was used to coat the powders. A detailed analysis of the coated copper or stainless steel powders shows a uniform nanocrystalline layer whatever the shape of the particles. The powders' coating process associates high efficiency for coating micro- and submicrometric powders, with a submicrometric or a nanometric layer having a similar chemical composition to the targets previously selected. A significant decrease of the crystallite size and an increase of high surface/volume ratio, are suitable to improve their friction coefficient, wettability and sinterability. The thermal evolution of the coated powders was studied using a hot chamber coupled to XRD and DTA-TG apparatus. The coated copper powders show above $700^{\circ} \mathrm{C}$ the formation of a typical intermetallic phase $\mathrm{Cu}_{4} \mathrm{Ni}$, that occurs in bcc stainless steel, where copper is an alloy element, and no vestiges of the coating is detected after heat treatment. The stainless steel coated powders reveal the formation of $\mathrm{Fe}_{4} \mathrm{Cu}_{3}$ at temperatures higher than $900{ }^{\circ} \mathrm{C}$.
\end{abstract}

(C) 2008 Elsevier B.V. All rights reserved.

\section{Introduction}

Powder metallurgy (PM) has attained an important role in different industrial fields, from structural parts to magnetic components. The European market turnover six billions of euros year and the annual worldwide metal production exceeds one million tonnes [1]. Stainless steel and copper have an important role as feedstock in PM industry. However novel materials are needed to improve their manufacturability and/or final properties.

Besides copper be frequently considered a desirable element in stainless steels parts as an alloy element being a substitute of $\mathrm{Ni}$, two different composites based on SS can be produced by PM [2-4]. In PM of stainless steel, through the addition of copper to stainless powders it is possible to decrease the melting/sintering temperature of austenitic stainless steel and sintering with a liquid phase. This could represent a good contribution for decreasing the undesirable swelling of specimens after densification processes. Previous research work have shown that electrolytic deposition of copper in iron powder improves the quality of the sintered parts by decreasing the porosity and promote a high diffusion of copper through the pores on sintering [5]. However, a recent study of uniaxial pressure followed by sintering of these feedstocks, reveals an important

\footnotetext{
* Corresponding author.

E-mail address: jose.castanho@dem.uc.pt (J.M. Castanho).
}

heterogeneity concerning the longitudinal and cross sections of the specimens. In longitudinal section the shrinkage is notorious, but in cross section the swelling is important, decreasing from the outside to the inside of the specimen [5]. The authors attribute this behaviour to the variation of friction and wear between copper and the dies during shape forming. Nevertheless, a lack of adhesion between matrix and coating due to the technology used to deposit the coatings could be also responsible. The detachment of different quantities of copper during shape forming and sintering induces movement of copper along of the main die axes toward the inside of the specimen, leaving an important percentage of porous outside [5].

Concerning the inverse copper matrix with austenite stainless steel, it has found a renewed interest for conductors in pulsed high-field magnets applications. This hybrid material must also induce ductility and mechanical strength [6]. A nanocomposite of nanocrystalline stainless steel in copper matrix could have an important function in the announced applications, but the role of the coating in manufacturing processes of parts and devices must not be forgotten.

The aim of the present study is to evaluate the efficiency of composite powders resulting from sputtering of pure copper or austenitic stainless steel targets on austenitic stainless steel or copper powders, respectively.

After a detailed analysis of the coated and uncoated powder characteristics, particularly concerning the soundness of the 
G Model

Table 1

Properties of coated and uncoated powders.

\begin{tabular}{|c|c|c|c|c|c|}
\hline Powder & $D_{50}(\mu \mathrm{m})$ & Real density $\left(\mathrm{g} \mathrm{cm}^{-3}\right)$ & Poured density $\left(\mathrm{g} \mathrm{cm}^{-3}\right)$ & Tap density $\left(\mathrm{g} \mathrm{cm}^{-3}\right)$ & Interparticulate friction $(\mathrm{Pa})$ \\
\hline $316 \mathrm{~L}$ & 7.7 & $7.83 \pm 0.01$ & $3.33 \pm 0.04$ & $4.38 \pm 0.01$ & $196 \pm 3$ \\
\hline 316L coated & 8.3 & $7.93 \pm 0.06$ & $3.16 \pm 0.05$ & $3.99 \pm 0.05$ & $54.1 \pm 0.9$ \\
\hline 316LHD & 61.2 & $7.98 \pm 0.07$ & $2.72 \pm 0.06$ & $3.35 \pm 0.01$ & $26.6 \pm 0.6$ \\
\hline 316LHD coated & 82.39 & $7.85 \pm 0.01$ & $2.66 \pm 0.02$ & $3.14 \pm 0.01$ & $26.1 \pm 0.2$ \\
\hline Cu sph. & 28.70 & $8.80 \pm 0.01$ & $4.83 \pm 0.1$ & $5.80 \pm 0.05$ & $189.5 \pm 5.8$ \\
\hline Cu sph. coated & 23.11 & $8.91 \pm 0.08$ & $4.89 \pm 0.09$ & $5.39 \pm 0.03$ & $35.9 \pm 0.7$ \\
\hline $\mathrm{Cu}$ irr. & 19.77 & $8.50 \pm 0.01$ & $2.56 \pm 0.05$ & $3.10 \pm 0.02$ & $50.1 \pm 1.0$ \\
\hline $\mathrm{Cu}$ irr. coated & 20.12 & $8.70 \pm 0.10$ & $2.49 \pm 0.04$ & $3.01 \pm 0.02$ & $61.0 \pm 1.0$ \\
\hline
\end{tabular}

coating during the conformation process and friction, the phase evolution with temperature up to sintering the temperature of the different powders are studied.

\section{Experimental procedure}

Micrometric commercial copper (99\% purity) and austenitic stainless steel 316L powders with two different shapes: irregular and spherical were used as the starting material. The chemical composition of the uncoated stainless steel powders (SS) is summarized in Table 1.

The powders were coated using a homemade dc magnetron sputtering system with a vacuum chamber equipped with a powder vibration system and a continuous powder feed system. Copper or stainless steel 304L (AISI) targets were used in order to coat the stainless steel or copper powders, respectively. The deposition parameters were constant in all depositions and were as follows: the deposition pressure of argon (99.999) was $5 \times 10^{-1} \mathrm{~Pa}$, after a previous chamber evacuation down to $10^{-4} \mathrm{~Pa}$, and the density discharge power was $16.7 \mathrm{~kW} / \mathrm{m}^{2}$. During deposition, the powders were continually shaken by a high frequency vibration system in order to obtain homogeneous coatings.

The phase evolution of SS 316L powders coated with copper and of copper powders coated with SS 304L, were evaluated by thermal analysis DTA-TG (SETARAM) equipment at a heating rate of $20^{\circ} \mathrm{C} / \mathrm{min}$ in an Argon atmosphere. Furthermore, it

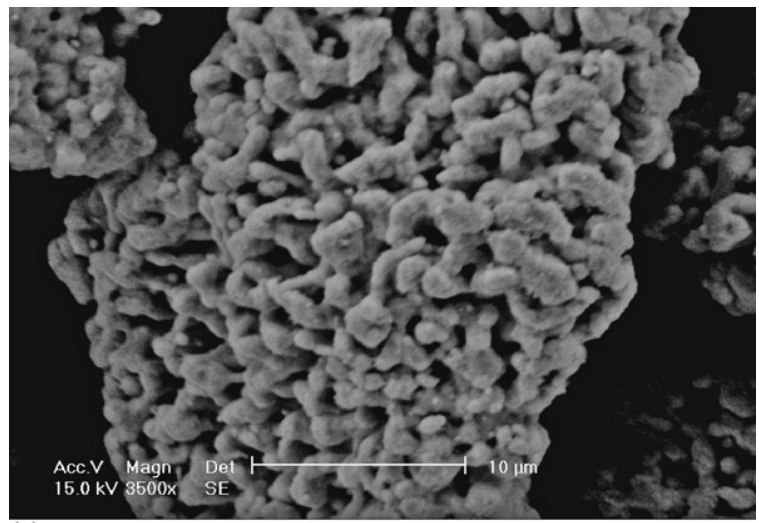

(a)

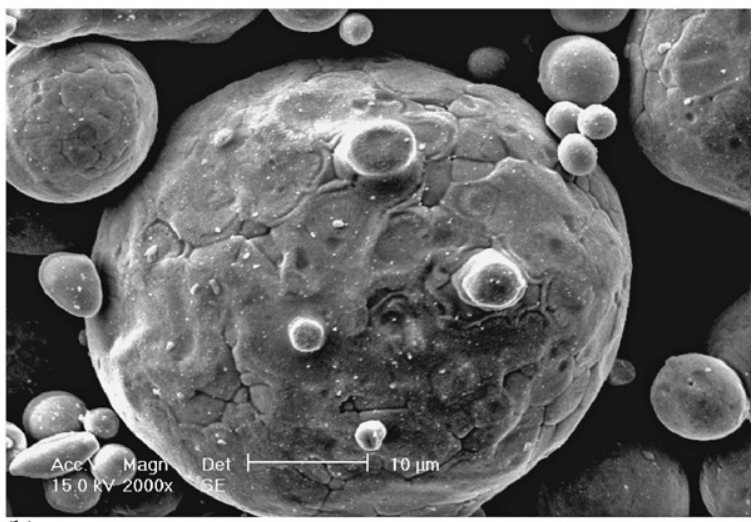

(b)

Fig. 1. Morphology of copper coated powders: (a) irregular and (b) spherical particles. was also used an X-ray diffractometer (XRD), Phillips X-Pert, in $\theta-2 \theta$ geometry in a Bragg-Brentano configuration, and a $\mathrm{Co}(\mathrm{K} \alpha)$ radiation. The system can be coupled to a hot chamber $\left(1500^{\circ} \mathrm{C}\right)$ allowing heating rates of $40^{\circ} \mathrm{C} / \mathrm{min}$ and different isothermal treatment in $\mathrm{Ar}+\mathrm{H}_{2}$ atmosphere to be performed. The maximum temperatures selected in this study were in accordance with the conventional sintering cycle of each material. Hence SS 316L powders coated with copper were heated up to $1300^{\circ} \mathrm{C}$ and copper powders coated with SS $304 \mathrm{~L}$ were treated up to $900^{\circ} \mathrm{C}$.

In order to determine the morphology and topography of the surfaces, the samples were observed in scanning electron microscopy (SEM) with a Philips-XL30.

The coated and uncoated heat-treated specimens were characterized concerning particle size distributions using a laser scattering (Coulter LS130). Tap density was determined according to the standard ISO 3953, and the flowability was evaluated by a Flodex Hanson Research flowmeter [7], in which the powders are allowed to fall freely from a cylindrical cup with a variable circular hole in the bottom. The diameter of the hole that allows powders to fall is designated by critical diameter and used in Eq. (1) to determine the interparticulate friction $k$

$k=\frac{\operatorname{grd}_{\text {pour }}}{2}$

where $g$ is the gravity acceleration, $r$ is the radius of the hole and $\left(d_{\text {pour }}\right)$ is the poured density the powders.

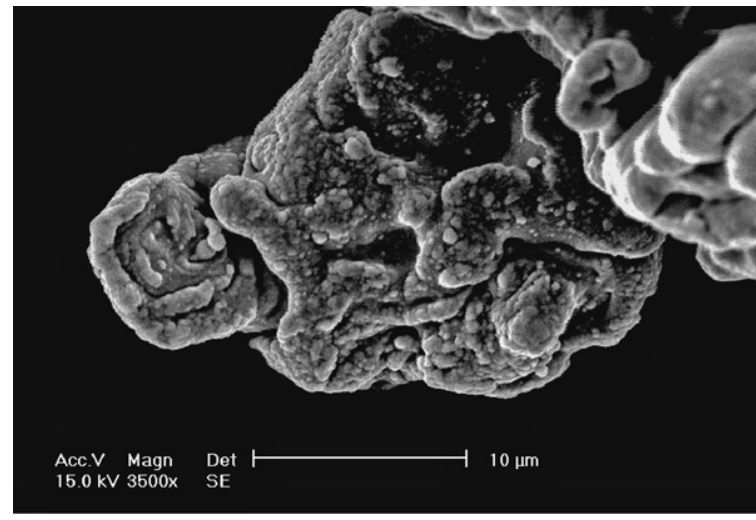

(a)

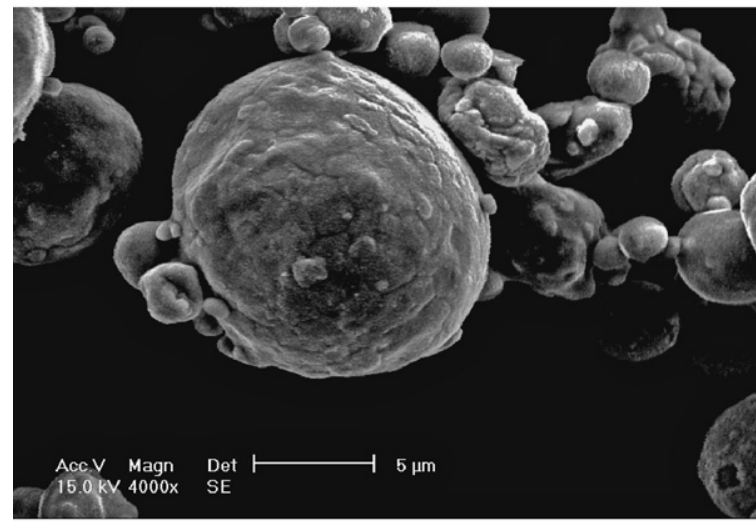

(b)

Fig. 2. SEM micrographs of SS 316 coated powders: (a) 316LHD with irregular and (b) 316L with spherical particles. 


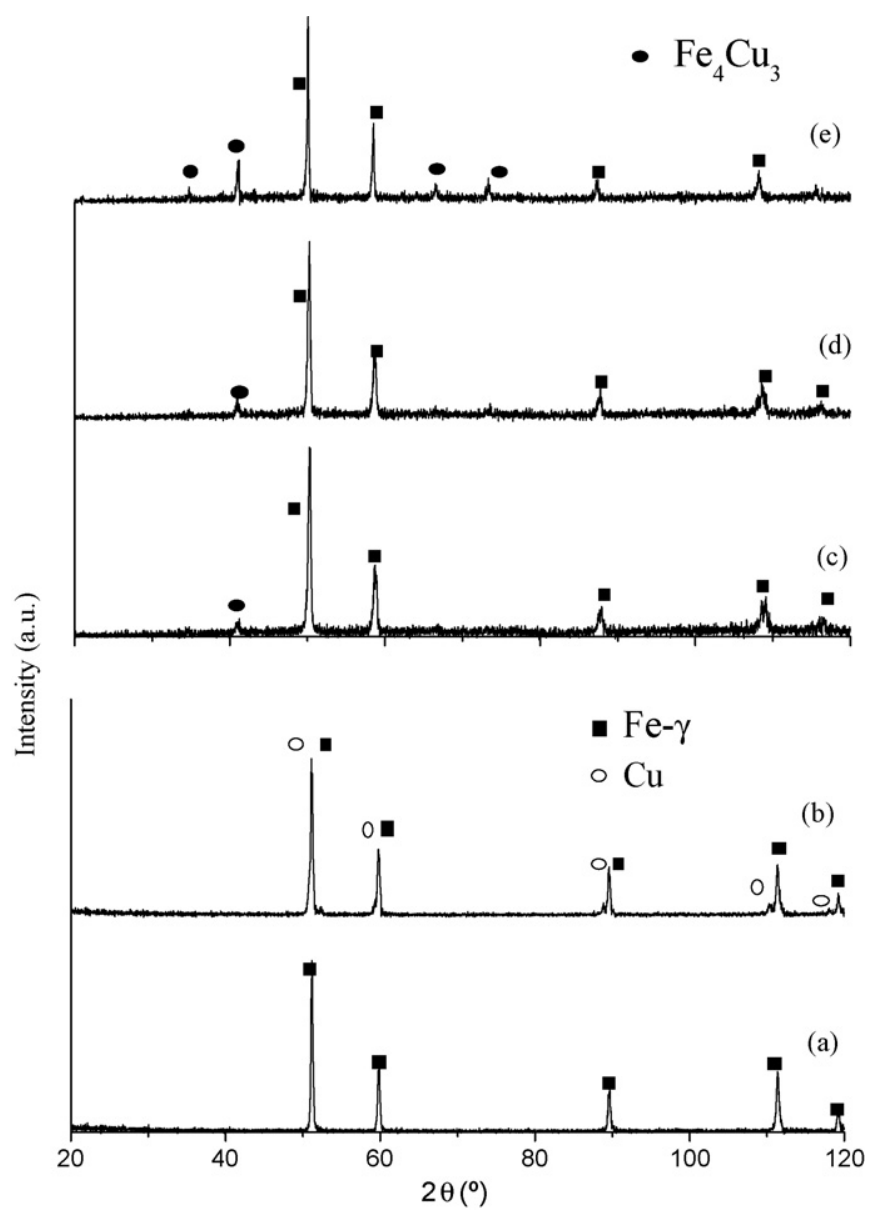

Fig. 3. XRD diffractograms of SS 316L powders: (a) uncoated, (b) coated with $\mathrm{Cu}$ (b) and after heat treatment at (c) $900^{\circ} \mathrm{C}$, (d) $1000^{\circ} \mathrm{C}$ and (e) $1300^{\circ} \mathrm{C}$.

\section{Results and discussion}

The surface morphology of the coated powders shown in the SEM micrographs (Figs. 1 and 2) depends on the shape of the uncoated powders. The coated powders present a blunt morphology cauliflower type and the particles were coated homogeneously showing an efficiently coverage of the starting particles independently of their shape.

The evolution of the structural properties of the studied alloys was investigated by X-ray diffraction (XRD). The diffractograms for uncoated and coated SS 316L and copper powders are shown in Figs. 3 and 4, respectively. After coating the SS 316 powders, the XRD results show an fcc copper structure besides the fcc austenite phase related to the uncoated powders (Fig. 3). The coated copper powders show a bcc $\alpha^{\prime}$ phase (martensitic type) and an fcc Cu phase related to the uncoated copper powders (Fig. 4).

The films deposited by sputtering from a SS 304L target have a bcc magnetic structure induced by the stress state during deposition. Thus, the copper coated particles exhibit magnetic properties due to the presence of this thin layer. The copper and SS thin films deposited on the powders, turn the microcrystalline surface into nanocrystalline.

The particle size distribution, density and the interparticulate friction of the $\mathrm{Cu}$, Cu coated, SS 316L and SS 316L coated powders are summarized in Table 1 . The presence of a thin film on the surface of the spherical particles induces a remarkable decrease of the interparticulate friction. On the other hand, the irregular shaped particles present a constancy of the interparticulate friction and the

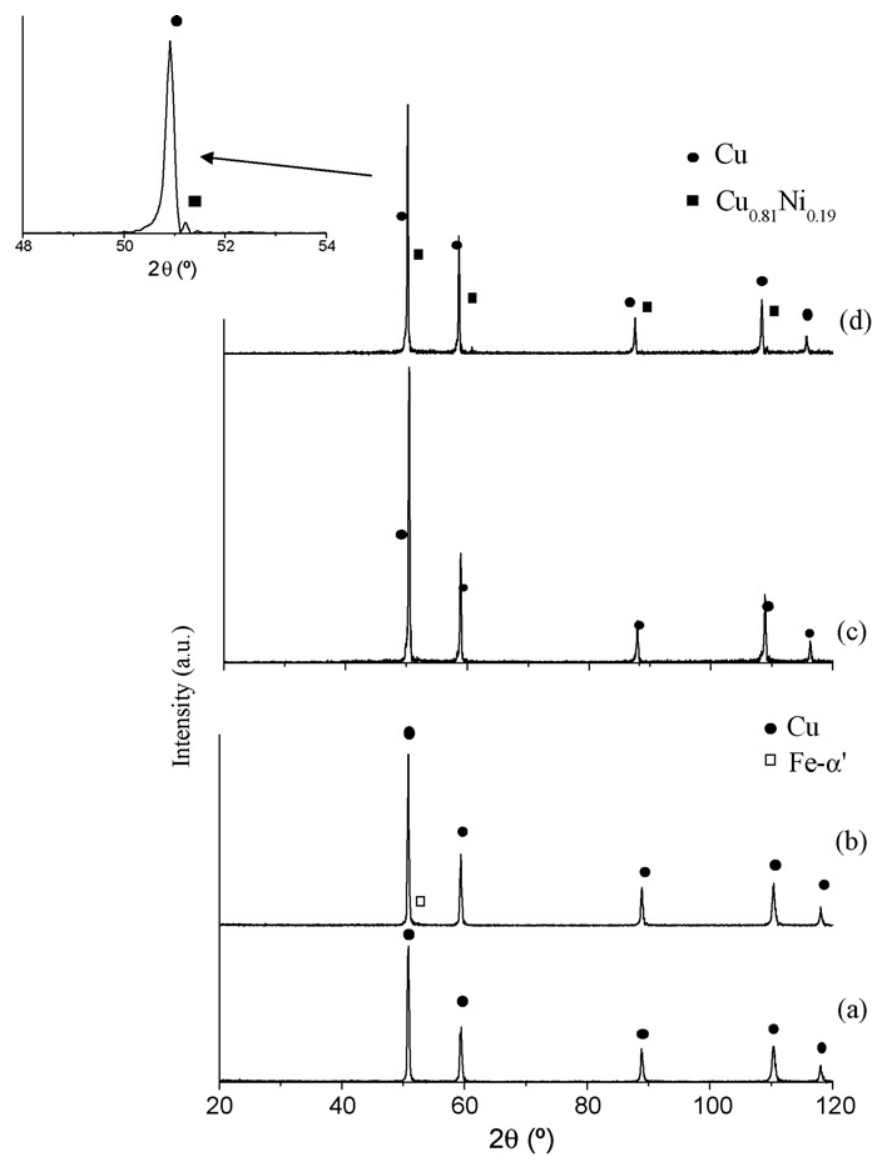

Fig. 4. XRD diffractograms of Cu powders: (a) uncoated, (b) coated with SS 304L and after heat treatment at (c) $700^{\circ} \mathrm{C}$ and (d) $900^{\circ} \mathrm{C}$.

coated copper powders even show a slight increase of the friction due to the magnetic properties of the SS coating.

In order to minimize oxidation, the samples were heated in a hot chamber $\left(1500^{\circ} \mathrm{C}\right)$ coupled to XRD in a flowing hydrogen-argon atmosphere. Starting at $27^{\circ} \mathrm{C}$, the heating temperature was raised $\left(40^{\circ} \mathrm{C} / \mathrm{min}\right.$ ) to $900^{\circ} \mathrm{C}$ and $1300^{\circ} \mathrm{C}$ for the copper and SS $316 \mathrm{~L}$ powders, respectively. These temperatures were selected based on the sintering temperature of conventional powders. X-ray diffractions of SS powders coated with copper after heat treatment at temperature above $900^{\circ} \mathrm{C}$ show the formation of a new phase, $\mathrm{Fe}_{4} \mathrm{Cu}_{3}$, resulting from the reaction of the copper phase with the coating (Fig. 3). After cooling to room temperature, besides the presence of $\mathrm{Fe}_{4} \mathrm{Cu}_{3}$ phase there is also the formation of some oxides. The $\mathrm{Fe}_{4} \mathrm{Cu}_{3}$ phase was also detected by Dan et al. [8] by annealing at $500^{\circ} \mathrm{C}$ stainless steel copper ions implanted. On the other hand, the XRD of copper powders coated with SS, at temperatures above $700^{\circ} \mathrm{C}$, shows the formation of $\mathrm{Cu}_{0.81} \mathrm{Ni}_{0.19}$ (Fig. 4). This intermetallic phase is mainly concentrated in the surface and sub-surface layer [9] and results from the diffusion of the nickel in the stainless steels matrix and the copper atoms.

\section{Conclusions}

Nanostructured composite metallic powders can be produced by an innovative use of the sputtering technique. Metallic targets, with the same chemical composition of the required coating, with similar sputtering conditions show an efficiently coverage of the powders whatever their shape. 
The behaviour of powders during the conformation process is strongly driven by their interparticulate friction and consequently their flowability. $\mathrm{Cu}$ and austenitic stainless steel powders show a significant decrease of the interparticulate friction after sputtering by creating submicrometric layers on powders. The coating's effect on these powder characteristics is much more noticed if they are spherical-shaped.

The phase evolution of the coated powders during sintering show the formation of intermetallic phases: $\mathrm{Fe}_{4} \mathrm{Cu}_{3}$ in SS powders and $\mathrm{Cu}_{4} \mathrm{Ni}$ in the other ones. No vestiges of the as-deposited coating are detected on copper powders after heat treatment.

In spite of this study is a part of a research program, as a final conclusion it is clear that coating by sputtering stainless steel powders could improve shrinkage and chemical homogeneity of the sinter parts. For the other powders the manufacturing process could gain quality, but the total disappearing of stainless steel coatings in benefit of intermetallic compound seems to be inappropriated.

\section{Acknowledgement}

This research was financial supported by a grant from the Portuguese Foundation for Science and Technology (FCT) under the $\mathrm{POCI} / \mathrm{CTM} / 59905 / 2004$ project.

\section{References}

[1] J.R. Moon, in: EPMA (Ed.), Introduction to PM, Training Course for Young Materials/Design Engineers, Kosice, Slovakia, 2007, pp. 1-21.

[2] M.V. Cleemput, H. Jones, M. Burgt, IEEE Trans. Magnet. 32 (4) (1996) 2466-2469.

[3] T. Sourisseau, E. Chauveau, B. Baroux, Corros. Sci. 47 (2005) 1097-1117.

[4] Copper Development Association for Copper and Brass Industries in the USA Industrial Powder Metallurgy-Copper in Iron and Steel P/M parts, 25-08-2007, http://www.copper.org.

[5] M. Kupková, M. Kupka, S. Strobl, M. Cerny, G. Khatibi, C. Gierl, Scripta Mater. 57 (2007) 639-642.

[6] W. Grunberger, M. Heilmaier, L. Schultz, Mater. Lett. 52 (2002) 154-158.

[7] A. Gioia, Flodex Technical Bulletin, Hanson Research Corporation, 1980.

[8] Z.G. Dan, H.W. Ni, B.F. Xu, J. Xiong, P.Y. Xiong, Thin Solid Films 492 (2005) 93-100.

[9] Y.S. Kwon, V.V. An, A.P. Ilyn, D.V. Tikhonow, Mater. Lett. 61 (2007) 3247-3250. 